\title{
Consensus as a Prerequisite for Quality in Early Child Care: The Dutch Case
}

\author{
Paul Vedder \\ Ellen Bouwer \\ Leiden University, The Netherlands
}

\begin{abstract}
The rapid growth in the number of nurseries and playgroups in the Netherlands since 1990 has given an impetus to concerns about the quality of these provisions. We argue that parents and staff should define the educational goals that are needed to evaluate the quality of education in child centers. Using data from two surveys, one with child care center staff and one with parents, we will show that on a general level there seems to be an overlap in goal preferences of parents and staff. A closer look, however, reveals a lack of agreement about important goals. Communication between caregivers and parents about educational goals and practices has to be improved. We also make some recommendations for improving the relationship between staff and parents aimed at building consensus about the goals of education in child care centers.
\end{abstract}

In this article we will describe consensus-building between parents and staff of centers for early childhood care and education (henceforth ECCE) as the core of attempts to define and improve the quality of education in centers for child care. We assume that such consensus is needed, since in democratic societies goals and educational practices designed to achieve them can only find justification in either tacit or explicit consensus between all parties involved (Bouwer \& Vedder, 1995; Vedder, Bouwer, \& Pels, 1995). ${ }^{1}$

Correspondence should be addressed to Paul Vedder, Center for Intercultural Pedagogics, P.B. 9555, 2300 RB Leiden, The Netherlands. The study reported in this article was funded by the Center for Science and Research of Leiden University and the Bernard van Leer Foundation. We thank Iram Siraj-Blatchford (University of London), Mariska Kromhout (Leiden University), and two anonymous reviewers for comments on earlier drafts of this article.

'The notion of consensus on goals and practices in education is typical for the educational theories of the 1970s that stressed the reproductive function of education. In these theories the concept of consensus was linked to the assumption that education is neutral and transmits commonly held social values. Theories like those of Althusser 


\section{Defining Quality in Early Childhood Education}

In recent years, many studies have been conducted on the quality of ECCE. We distinguish three approaches in the quest for quality: the structural indicators approach, the process approach, and the goaldirected approach.

\section{Structural Indicators Approach}

In the structural indicators approach the focus is on indicators like the regulation of child care in laws, financial conditions, staff training requirements, and staff-to-child ratio. This is inspired by policy measures and policy documents and concerns mainly aspects of the organization of ECCE that can be influenced relatively easy by policy measures.

\section{Process Approach}

The process approach focuses on what happens to children in the provision of care. Important in this approach are interactions between staff and children, the curriculum, and health and safety. The process approach is often based on psychological and educational theories of development and learning. The Early Childhood Environment Rating Scale (ECERS) is a well-known and often used "process" measure of the quality in ECCE (Andersson, 1995) It is frequently suggested that the process approach takes full account of the nature of children's learning and development.

We all know very well that children's cognitive or social development cannot easily be socially constructed. Children's development has a dynamism of its own. Children may not be capable of doing things educators would like them to do, or they may simply not "feel like" doing these things. Moreover, they learn and develop regardless of the educators' goals. This knowledge about child development and learning is seen in the process approach as justification for taking resources that are available to the children for their development and learning as a starting point for defining the quality of ECCE. What counts in this approach is the variety of knowledge and skill resources made available to children and the depth of children's involvement in using the resources (cf. Laevers, 1994).

and Bowles and Gintis stated that educational institutions and practices in these institutions simply reflected the power structures in society (for an overview see May, 1994). Here we use the notion of consensus in a different, more strategic way: consensus is needed to create group-based power to achieve changes that the group considers important. 


\section{Goal-Directed Approach}

The goal-directed approach is based on the notion that in order to be able to distinguish good from bad and best from better educational practices, we need to perceive these practices as steps towards goals that educators value. If we do not know which goals are important in education, we cannot discuss the quality of its practices. Goals specify particular products of learning and development that can be brought about by education. They represent knowledge and value domains that are typical for (sub)cultures, and they are deemed important for the (sub)cultures' reproduction or innovation. Quality in education is about the extent to which these goals are achieved and about how this happens in the context of the extent to which it interferes with the achievement of other important goals. Since the quality of education is a public issue, educational goals need to be justified by some kind of consensus among the different parties involved in education. Such consensus has to be established in public discussions. In what follows we also refer to this goal-directed approach as the consensus-building approach.

We favor the goal-directed approach for several reasons: 1) More directly than the other approaches, it leads to guidelines for choices about programs and pedagogical methods. 2) It contributes to the definition of clear standards for the evaluation of the quality of ECCE. And 3) it works towards a clear, controllable justification for the standards. Our preference for the consensus-building or goal-directed approach may be illuminated by the following comments on some proposed quality standards according to the process approach.

Psychologists working in the field of early childhood education hardly reflect on the need for defining educational goals and finding justification for them (see, however, Moss, 1988). They either assume or anticipate consensus about a particular goal. For instance, they may assume that an intelligence test is a good instrument to measure the goal "prepared children for the cognitive requirements of primary school." Their research informs us about the means that are effective in raising intelligence test scores. At the same time, other studies show what would be effective means for stimulating children's social development. A list such as that in Table 1 (Melhuish, 1993) may be the result.

Although the variables in Melhuish's list refer to educational practices, it is not an agenda for an educational program. This is particularly evident in the variable "developmentally appropriate activities." We will do not know what these are. Clarke-Stewart (1991) suggests that they might be programs with more prescribed educational activities like lessons, guided play sessions, and the teaching of specific content. Using such a program leads to higher scores on intel- 


\section{Table 1 \\ Proximal Variables Indicating the Quality of Education in Child Care Centres}

Variable

Specification

Adult-child interaction:

Peer interaction:

Interpersonal relationships:

Developmentally appropriate activities:

Health and safety:

Emotional climate "happiness":
Sensitive responsiveness, communication, emotional security

More interaction-social skills improve

Attachment, stability of relationships

Most appropriate situations defined by zone of proximal development

A.o. disease control

Active, happy, involved children; happiness makes learning easier

Adapted from Melhuish (1993)

ligence and achievement tests but, as we will see in the next section, many parents do not emphasize this educational goal, and certainly not if its achievement involves more prescribed and limited educational activities. Moreover, the list does not give clues about how to balance particular goals and practices. Involvement in cognitively enriching, prescribed educational activities might restrict children's opportunities for peer interaction, meaning that children might have fewer opportunities to develop social skills. This and comparable lists clearly have their shortcomings: they assume consensus about goals and they lack clues as to which choices should be made regarding the curriculum or activity program.

\section{Early Childhood Care and Education in the Netherlands}

Most centers for early childhood care and education in the Netherlands are either nurseries or playgroups. In 1992 the Central Bureau for Statistics (Central Bureau of Statistics, 1993) counted 3766 playgroups and 1399 nurseries. Nurseries cater to parents' needs for care and education for their 0 to 4 year old children while the parents are working. They are open five days a week for at least nine hours a day. 
Most children attend whole days, at least two days per week. A playgroup is meant for children for age 2 (or 1-1/2) to 4. Playgroups are seen more as providing relief for parents for just a few hours of a few days in a week. Although most nurseries and playgroups are subsidized by the national administration through local authorities, parents have to pay a fee per child depending on the parent's income.

Through the subsidies, the administration has an important impact on the quantity of child care places, but so far few measures have been taken to influence their quality. The most important instrument available to the government to influence the quality of ECCE is the stipulation of requirements for the qualification of caregivers in nurseries and playgroups. Such measures are typical of the structural indicator approach. In 1993, when the former Minister of Health and Welfare took the initiative to install a committee to advise her on the quality of child care, it looked as if we would get new instruments to influence quality at a national level. The committee adopted a process approach and formulated several recommendations, in one of which the committee stressed the importance of good activity plans. It was deemed the responsibility of staff and, when possible, of the parents as well, to define these (Commissie Kwaliteit Kinderopvang, 1994). However, the recommendations did not lead to new national legislation, policies, or rules on the quality of child care.

Up until now there has been no national discussion in the Netherlands on the quality of child care that has led or leads to a clarification of educational goals and acceptable, adequate means that are in writing and prescribed in legislation. Each municipality can formulate its own policy on child care centers. They can find some support in a set of rules drafted by the association of Dutch municipalities (henceforth VNG; VNG, 1991). These rules specify some requirements concerning safety, hygiene, insurance, group size, opening hours, number of square meters per child, and minimum qualifications for staff. Concerning pedagogical quality, no minimal requirement is defined (VNG, 1991, p. 14).

At the moment, attempts are being made by center staff and coordinating bodies working in the field of child care to define quality standards for ECCE (Hopman, 1990; Mostert, 1992). The Netherlands Institute of Care and Welfare (NIZW), an organization supporting a broad variety of welfare institutions, has initiated a working group with the same mission (Pot, 1991). These are important steps to initiate a public discussion, but so far the impact has been small. At present, in the Netherlands, discussions in which people try to reach consensus about educational goals for ECCE seem to be possible only between the parents and staff of child care centers. Other parties are reluctant or hesitate to participate.

It is important to involve parents in defining the quality of child 
care. Playgroups and nurseries have been started in the past to supplement or to replace home education. Parents have initiated or promoted the start of these programs and still contribute financially and in many other ways to their functioning. Parents have vested interests in ECCE. This as well as the functioning of the centers as supplements to or replacements for home education make parents the primary candidates for helping to define and construct good quality center care and education.

In the next section we will describe staff's and parents' goal preferences in centers for ECCE in the Netherlands and show that these preferences do not overlap to an extent that allows for the conclusion that the quality of education in the Netherlands is already based on a tacit consensus between staff and parents. In section 3 we will explore parent-staff contacts in Dutch centers and show that contacts aimed at consensus-building about goals and pedagogical approaches are almost absent. In the concluding section we will make some recommendations on how to improve staff-parent contacts aimed at consensus-building.

\section{Staff's and Parents' Ideas About Quality in ECCE}

To get a picture of what is happening at the moment in the practice of education for under fives in the Netherlands, we carried out a telephone survey with 80 child care centers (nurseries and playgroups) with ethnically mixed populations. We assumed that in these centers, more than in ethnically homogeneous ones, staff would have experienced the need for consensus-building on goals and practices, since they have to deal with a broad variety of cultural backgrounds, educational values, and practices. Most centers were located in the densely populated western provinces of the Netherlands, and a few were in the rural areas.

We also visited ten centers to analyze staff's pedagogical approaches. These were chosen from the 80 participating in the survey to represent a broad variety of approaches (Vedder, Bouwer, \& Pels, 1995). Six were located in one of the four biggest cities (Amsterdam, Rotterdam, The Hague, and Utrecht) and the other four were found in smaller cities in the southern, central, and eastern parts of the Netherlands. Five of the centers were nurseries and five were playgroups. During the visits we observed daily practices and had lengthy interviews with members of staff.

Most information from parents in this section comes from a recently conducted representative national survey among 153 families with children in nurseries (Van Dijke, Terpstra, \& Hermanns, 1994). One third of the respondents were fathers, the others were mothers. 
No immigrant parents participated. Sixteen nurseries were involved, two of which also participated in our study. Although the fact that we are comparing data from two different studies using different samples and different instruments means that part of the discrepancies or similarities we report may be due to these differences, we are confident about the validity of our findings. The reported findings about differences in preferences for educational goals and practices, based on a comparison between the studies, is in large part confirmed within each study, since center staff were asked about parents and parents were asked about staff.

\section{Center Staff}

Important Goals. The 80 centers' directors or deputies were asked to indicate whether or not they deemed particular predefined goals, some of which were clearly focused on multicultural education, to be important. Table 2 presents the goals and the coordinators' answers. "Teaching children respect for and acceptance of representatives of other cultures" is the most popular goal. Centers clearly want to take their responsibility for preparing children for their lives in a multicultural society. At the same time, however, many directors or deputies indicated that they disapprove of a goal focusing on cultural

\section{Table 2}

Directors' or Deputies' Answers to the Question Whether a Particular Goal is Important or Not

\begin{tabular}{|c|c|c|c|}
\hline & Yes & No & $?$ \\
\hline $\begin{array}{l}\text { Teach children respect for and ac- } \\
\text { ceptance of representatives of } \\
\text { other cultures }\end{array}$ & $74(93 \%)$ & $4(5 \%)$ & $2(3 \%)$ \\
\hline $\begin{array}{l}\text { Pay due attention to differences in } \\
\text { food and sleeping habits and to } \\
\text { hygiene }\end{array}$ & $62(78 \%)$ & $3(4 \%)$ & $15(18 \%)$ \\
\hline Prevent educational problems & $61(76 \%)$ & $7(9 \%)$ & $12(15 \%)$ \\
\hline Stimulate children's development & $52(65 \%)$ & $9(11 \%)$ & $19(24 \%)$ \\
\hline $\begin{array}{l}\text { Support parents in their education } \\
\text { and care }\end{array}$ & $46(58 \%)$ & $7(9 \%)$ & $27(34 \%)$ \\
\hline $\begin{array}{l}\text { Encourage the use and stimulate } \\
\text { the acquisition of minority chil- } \\
\text { dren's first language }\end{array}$ & $46(58 \%)$ & $31(39 \%)$ & $4(4 \%)$ \\
\hline
\end{tabular}


minority children, "Encouraging the use and stimulating the acquisition of minority children's first language."

Centers are least clear about supporting parents in their education and care. More than $30 \%$ of directors or deputies do not know whether this is an important goal. Some interviewees amended goals. One interviewee did this with the goal "Stimulate children's development." She put it this way: "A playgroup should not become a school. Children spend two years in Kindergarten in preparation for primary school. I think it is more important to give children the opportunity to play and have fun."

During our visits to nurseries and playgroups, 14 directors and deputies were asked to rank the following eight goals indicating what are the goals most important for the general quality of ECCE.

A Provide good physical care for children

B Provide a safe and familiar environment for children

C Prepare for primary school

D Detect developmental problems in children

E Stimulate children's development

F Pay special attention to the prevention of deprivation in children

$G$ Transmit particular values and standards to the children

$\mathrm{H}$ Stimulate the children to play together and to get to know each other better

All the centers but two put goal B ("Provide a safe and familiar environment for children") in first place. This is seen as a prerequisite for all the other activities. "Children's social relationships" $(H)$ is also an important goal domain. As in the telephone survey the goal "Prepare for primary school" was seen as least important. If we look at the average ranking the following list results:

1. B Provide a safe and familiar environment for children

2. H Stimulate the children to play together and to get to know each other better

3. E Stimulate children's development

4. A Provide good physical care for children

5. G Transmit particular values and standards to the children

6. F Pay special attention to the prevention of deprivation in children

7. D Detect developmental problems in children

8. C Prepare for primary school

Differences of opinion were seen most with "Provide good physical care for children" and "Pay special attention to the prevention of de- 
privation in children." Some of these differences can be attributed to the type of center: nurseries put more emphasis on providing physical care, playgroups seem to focus more often on the prevention of deprivation. Compare for instance the remark of the director of a nursery: "Simply being at a nursery means already that development is stimulated. If your work is done right, it will not be necessary to prevent deprivation," and the following remark made by the headmistress of a playgroup: "Active stimulation of the development of children is the main goal in our playgroup and for me this is closely linked to the prevention of deprivation."

Pedagogical Approach. We found that centers clearly differ in the type of development they want to encourage in children and in the intensity of developmental stimulation. Most centers use an open approach to the children, characterized by ample opportunities for free play, freedom of choice of activities, and a minimum of rules of conduct. Two centers used a more strict approach. In one of these, strictness is considered to be helpful to children in learning rules of conduct. In the other, the staff thinks that a structured approach is necessary because they are working with children who need extra language and cognitive stimulation. Of all the centers studied, this one pays the most attention to preparing children for school. All but one center lacked well-defined plains as to which developmental and learning goals they want the children to achieve.

All centers pay special attention to children with developmental problems, but caregivers often rely on their intuition and experience for stimulating children's development and detecting problems. In only one center do staff keep records of each child's development. Two other centers keep track of children's development but not in a systematic way. It seemed that caregivers generally have nothing but a rather global notion of individual children's developmental needs.

We also asked the centers whether they had adapted their pedagogical method to immigrant children. Half of the centers did not indicate any such adaptation. Five offer extra language stimulation to immigrant children, mostly in Dutch. Three say that they pay special attention to immigrant children's play and motor skills.

\section{Parents}

Important Goals. It was expected that parents' choice of a particular setting, for instance a nursery, would be linked to the educational goals which they would like the education in that setting to emphasize. In order to study their expectations, nursery parents were asked during the interview to describe what they would feel would be the 


\section{Table 3 \\ Words Used by Parents to Describe the \\ Optimal Climate or Atmosphere in Nurseries \\ (in Percentages of all Words Used by Parents)}

friendly, cozy

warm, caring

structured, strict

quiet

stimulating

Adapted from Van Dijke, Terpstra, \& Hermanns (1994)

ideal climate or atmosphere in the nursery. There were no restrictions on the number or kinds of words they could use. A lengthy list was the result, but two words were clearly favored: friendly and cozy. Table 3 presents an overview of the most-mentioned words. The numbers are percentages of the total number of words mentioned by the parents. Most parents stressed the importance of a place where children feel safe and secure, where they are loved and cared for. Words referring to the training and experience of caregivers were hardly used.

Parents were also asked to choose from the following list the three goals of child care education they valued most and the three they valued least:

A Learn rules of social conduct (examples: don't steal or cheat, remain seated while eating)

B Acquire knowledge (color names, seasons, counting, names of animals and plants, etc.)

C Stimulate fantasy, creativity, and imagination

D Develop social competence (playing and learning together, listening to others, sharing)

E Freedom (Children should be allowed to do what they feel like, and they should have plenty of room to play freely.)

F Motor development (stimulate good motor development)

G Preparation for school

$\mathrm{H}$ Celebration of holy days and festivals (Christmas, Halloween)

I Language development

In Table 4 we present the results. Many parents chose the development of social competence as a highly valued educational goal. Stimu- 


\section{Table 4}

\section{Educational Goals for Nurseries in the Netherlands Favored Most or Least by Parents (in Percentages)}

\begin{tabular}{lrr}
\hline & High & Low \\
\hline social conduct & 20 & 5 \\
knowledge & 3 & 18 \\
fantasy & 25 & 2 \\
social competence & 29 & - \\
freedom & 6 & 18 \\
motor development & 4 & 13 \\
preparation school & 3 & 24 \\
festivities & 5 & 13 \\
language development & 5 & 8 \\
\hline
\end{tabular}

Adapted from Van Dijke, Terpstra, \& Hermanns (1994)

lating fantasy, creativity, and imagination and learning rules of social conduct were also chosen by many parents. As least favored goals the preparation for school received most choices. Giving children the room to do what they like and acquiring knowledge are two other goals which are deemed to be of relatively little value.

As stated before, the Van Dijke, Terpstra, and Hermanns (1994) study does not yield information about immigrant parents' goal preferences. From other studies (Eldering \& Vedder, 1992; Pels, 1991; Vedder, 1995) we know that immigrant parents in the Netherlands find it very important that their young children learn Dutch in nurseries and playgroups and that they are being prepared for primary school by learning letters and numbers. They are concerned that goals they deem even more important, like respecting adults and obedience, might be undermined by the centers' attention for openness, free play, and autonomy in making choices for activities.

Pedagogical Approach. Parents were also asked whether they are satisfied with the way caregivers deal with their children in such areas as signaling what is going on in a child, punitive measures, eating, comforting, hugging, solving conflicts between children, singing, and story reading. With respect to all of these aspects between 80 and $97 \%$ of the parents were satisfied, while between 1 and $6 \%$ of parents were not satisfied or not always satisfied. Regarding punitive mea- 
sures, $19 \%$ of the parents did not really know what was happening in their child's nursery. The same holds for more specific categories like solving conflicts between children.

When staff and parental goal preferences were compared, there seemed to be a consensus between staff and Dutch (i.e., non-immigrant) parents on the importance of particular goals and on the pedagogical means to achieve them. Center staff and Dutch parents agree that centers should provide a safe and familiar environment for children and that good social relationships are important. They also agree that centers do not have much of a role to play in the preparation of children for primary school. Neither staff nor Dutch parents, however, comprise stable, homogeneous groups in respect to preferences for goals and educational practices. Caregivers from different centers disagreed about the importance of particular goals concerning children's physical care and, although most parents stressed the importance of teaching rules of conduct and the stimulation of social development, a number of parents clearly preferred other goals, like preparing children for school and teaching children world knowledge.

The latter goals are also very important to many immigrant parents. But even as they also stress the importance of children's social development and social conduct, there is a difference between how most Dutch parents and how many immigrant parents perceive it. Many of the Turkish, Moroccan, Surinamese, and Antillian parents in the Netherlands do not speak primarily of peer relationships, as most Dutch parents and center staff do, but of adult-child relationships. Children have to learn to respect adults.

Another tension exists between many parents' wish for their children to learn rules of social conduct and centers' use of an open approach to children, characterized by ample opportunities for free play, freedom of choice of activities, and a minimum of rules of conduct.

The conclusion to be drawn is that in the Dutch society a tacit consensus about educational goals and approaches in centers for ECCE cannot be found. There is a clear need to work towards consensus.

\section{Staff-Parent Contacts}

Consensus-building between parents and staff of child care centers is possible only when they communicate with each other and seek ways to share the responsibility for the education of the children. In our survey we wanted to find out how far staff and parents have come in this respect. 


\section{Staff About Parents}

We explored the parents' role in centers' policies and educational practices, using staff members as informants. In all of the centers, contacts with parents were seen as important and were often considered essential to the establishment of relationships with parents based on mutual trust. "If parents feel at home in the center, so will their children." Parent contacts were also said to be a help in exchanging information about the children and their backgrounds. When asked what the center had to offer to the parents, the answers were twofold: to give support and relief in the education and care of the children, and to function as a place where parents can meet other parents.

Staff of 54 of the 80 centers in our survey $(68 \%)$ made no home visits. Staff of seven centers (9\%) made annual home visits, staff of two centers (3\%) made more than one such visit per year, and 15 centers (18\%) reported that they made home visits but at a rate of less than once per year. For the other two centers, no information on this point is available.

Informal contacts were an important instrument in parent-staff communication. In most centers parents were given the opportunity to sit down and drink a cup of coffee or tea in the morning when they brought their children. All centers organized one or more formal parent meetings a year.

We were also interested in the participation of parents in parents' committees. Forty-three centers (54\%) had a parents' committee. These committees advice and support staff, but the staff decides what to do. This is a clear limitation on the committee's influence. We encountered only one center in which some power was given to the parents' committee, in that it had to approve of the center's policy plan.

Since parents' opportunities to influence a center's operation through a parents' committee are limited, it is important for them to have other ways to let their voice be heard. In a few centers, staff explicitly asked parents whether they have particular wishes or needs, but most of the time the parents themselves have to take the initiative. One center placed a suggestion box in the center, inviting parents to express their needs, wishes, and complaints. Another had taken a survey amongst all parents as a step towards the improvement of the quality of work in the center in accordance with parents' wishes. In these centers, as in others, not all wishes were fulfilled. Often requests are taken into consideration only if the proposed change would benefit all of the children. Wishes concerning hygiene, food, or clothing of the children may sometimes lead to changes, but 
those regarding group size, curriculum, or opening hours are not open to negotiation.

\section{Parents About Staff}

For this perspective we again turn to Van Dijke, Terpstra, and Hermanns (1994). Their study shows that $29 \%$ of the parents whose children visit a nursery know little or nothing about staff's educational approach and goal preferences. All of the parents were asked whether their own educational approach corresponds to the one used by nursery staff. Eleven percent indicated that correspondence is lacking, and $9 \%$ said that their approach sometimes differs from the one used by nursery staff.

Parents were also asked in which domains they could influence staff's functioning. Table 5 presents the information, showing that a high percentage of parents is convinced that they can influence staff when it comes to the care of the parents' own child. Far fewer parents think they can influence aspects like the activity program, interior, employment policy, and general policy, and no parent thinks that he or she can influence the number of children in a group.

\section{Problematic Parent-Staff Communication}

Staff and parental evaluations of their mutual communication and influence suggest that this communication is far from optimal and that parents have little influence beyond what is going on in terms of the immediate care of their own child. Generally, staff stresses the importance of parental involvement to help parents feel at home in the center, and that their children are in good hands. Contacts with parents should also help staff in getting to know a child better, so that the staff can provide more understanding and support.

Actually, most parent-staff contacts that should contribute to the achievement of these goals take place when parents bring their children to the center or pick them up. Few centers organize home visits and none has tried to discuss matters of curriculum and pedagogical approach with parents. A noticeable finding in this respect is that more than half of the centers had parents' committees, but only one of these committees had a critical impact on decisions regarding curricular matters or pedagogical approach. This corresponds to what parents report about their influence on the organization of the care provisions.

Parents have little opportunity-or rarely take the opportunity-to participate in processes of consensus-building between staff and parents. There are probably several reasons for this. One is that center- 
based child care traditionally has strong autonomy, justified by the notion of the professional who knows what is good for children better than the non-professional parents. As a consequence professionals have never felt accountable to parents and contacts between parents and professionals have been minimal (cf. Singer, 1992). At the moment this "professionalism gap" is closing for Dutch parents, but it is still very wide for many immigrant parents, at least in their own perception. In our interviews, we heard more than once that immigrant parents think that caregivers know best what is good for their children, or with the words of one of the staff respondents: "Parents do see us as professionals. Some don't dare to talk to us and certainly wouldn't say anything that might be understood as a directive."

Another important reason is the shortage of places in child care centers. In a sense, many parents are glad to find a place at all where they can leave their children while they are working. They cannot be too critical or demand too much influence in the organization (cf. Van Dijke, Terpstra, \& Hermanns, 1994). A third reason is that it is difficult indeed to make clear statements about the quality of center care. As long as parents are seen as or behave themselves like individual consumers of care provisions who are mainly interested in the welfare of their own child, individual wishes will have to be weighed against the welfare of the group. Center care deals with individual children, but in a group context that cannot cater to a broad range of different individual wishes.

\section{How to Improve the Situation}

In the introduction, we noted our preference for a goal-directed approach to assessing and improving quality in ECCE, suggesting that within this approach some kind of consensus about goals for education in early child care centers is a prerequisite for evaluating and improving the quality of that education. We have clarified that, in the Netherlands, national and local administrations play only a limited role in defining these goals. They are mainly concerned with the availability of child care, health, and safety. Aspects of quality concerning children's intellectual, language, emotional, and social development are deemed to be staff and parental responsibilities.

Our presentation of goal preferences of staff and parents has shown that in each group, majorities can be identified agreeing on the importance of particular goals. At the same time, however, we have shown that there are disagreements about other goals as well as tensions between preferred educational goals and practices. The conclusion has to be that it is difficult to find explicit or tacit consensus about 
goals for ECCE that can be used to evaluate its quality. Parents' and professional caregivers' cultural backgrounds, their knowledge about the educational system and about child development, their capability to assess what is good for their children's development, their mutual dependencies, and many factors influence their goal preferences.

We have also explored what centers do to involve parents in discussions about the center's curriculum and pedagogical approach. Information from both staff and parents has shown that such discussions hardly take place. Parents and staff do have frequent talks about that parent's child, but educational goals and educational approaches are rarely discussed. These are seen as the staff's domain.

In consensus-building, staff should have an important initiating and regulating role. Reaching out to parents, however, is not easy. In this final section we would like to make some recommendations for the organization of the consensus-building process.

At an instrumental level, and to start with, center staff might take the following steps to facilitate parents' communication about their educational wishes and needs:

1. Make sure that parents feel welcome in the center and that they know that there is always a member of staff available for them to speak with;

2. When parents have had enough time to get used to the center routine and to become acquainted with some staff members, the center can use a more active approach, such as asking parents whether the child enjoys the center, whether attending the center has changed the child's language use, whether they have any ideas about the kinds of food, activities, or types of attention that would be good for the child or that would make the child's stay in the center more enjoyable or encouraging, and the like;

3. Staff might adopt a rule that if they do not know how to handle a child or how to get a child's attention, they will ask the child's parents what they think might be the best thing to do. Implementing such a rule eventually leads to a clear picture of the educational wishes and needs of children and their parents; and

4. When all of these steps have been taken, staff can start more formal discussions with parents directed at consensus-building.

For the quality of the consensus-building process, it is important that the participants realize that consensus is not a stable quality. The participants in the discussion may not always be the same people and those who repeatedly participate may change their ideas and preferences from time to time. This calls for opportunities to amend elements of the consensus once it is reached. Taylor (1991) suggests 
that the more attention given to the products of consensus-reaching, such as written charters or codes of conduct, the less chance there is of responding effectively to changes in participants' thinking and the more chance there is that consensus-seeking will lead to conflicts. This danger is real, but at the same time educating children requires some stability and continuity in programs and other means that are used to educate and teach them. Charters, pedagogical plans, and other written products can be a help in this respect, and can also function as a basis for brochures to inform new parents about the program of the center.

Consensus-building between parents and staff is clearly not an easy task. The choice of goals and decisions on which educational means are acceptable are closely linked to the values that are important to the parties involved. Especially when parents and staff of a center come from different ethnic, professional, or educational backgrounds, holding different religious and political ideas, it is very unlikely that they all will hold the same values to the same extent.

Bringing together people who hold different values can easily lead to conflicts. Therefore, centers and parents should try to match their goals. For the sake of reaching consensus, participants in the discussion will have to accept that some values will be represented in education in a different way or with a different intensity than each individual participant would have preferred. Discussions may also lead to the definition of new values as a new common ground based on different value preferences. When functioning in this way, consensus-building is really an in-service training process for staff and parents. Moreover, consensus-building would be a significant step towards bridging the emotional and cognitive gap between the home and the center.

\section{References}

Andersson, M. (1995). A Swedish version of the Early Childhood Environment Rating Scale. Stockholm: School of Education.

Bouwer, E., \& Vedder, P. (1995). Kleine verschillen [Small differences]. Utrecht: De Tijdstroom.

Central Bureau for Statistics (1993). Kindercentra [Child centers] 1992. Voorburg/Heerlen: Centraal Bureau voor de Statistiek.

Clarke-Stewart, K.A. (1991). A home is not a school: The effects of child care on children's development. Journal of Social Issues, 47, 105-123.

Commissie Kwaliteit Kinderopvang (1994). De kunst van de kinderopvang [The art of child care]. Utrecht: SWP.

Eldering, L. \& Vedder, P. (1992). OPSTAP: Een opstap naar meer schoolsucces? [OPSTAP: A step toward school success?] Amsterdam/Lisse: Swets and Zeitlinger.

Hopman, M. (1990). Gehechtheidsrelatie stelt hoge eisen aan crecheleidster [Attachment requires a lot from caregivers]. Kinderopvang 9, 5-7.

Laevers, F. (1994). The innovative project experiential education and the definition of 
quality in education. In F. Laevers (ed.), Defining and assessing quality in early childhood education. Leuven: Leuven University Press.

May, S. (1994). Making multicultural education work. Clevedon: Multilingual Matters.

Melhuish, E (1993). Preschool care and education: Lessons from the 20th for the 21st century. International Journal of Early Years Education, 1(2), 19-32.

Moss, P. (1988). Childcare and equality of opportunity. Brussels: Commission of the European Communities.

Mosterd, E. (1992). Maak eerst je pedagogische uitgangspunten zichtbaar [Show your educational principles]. Kinderopvang $12,12-13$.

Pels, T. (1991). Marokkaanse kleuters en hun culturele kapitaal [Moroccan pre-school children and their cultural capital]. Amsterdam: Swets and Zeitlinger.

Pot, L. (1991). Kwaliteit van kinderopvang in de steigers [Building quality in child care]. Utrecht: NIZW.

Singer, E. (1992). Child-care and the psychology of development. London: Routledge.

Taylor, M. (1991). Values in education: A comment. In I. Barr and H. Hooghoff (eds.), Values, schooling and society. The Hague: CIDREE.

Van Dijke, A., Terpstra, L., \& Hermanns, J. (1994). Ouders over kinderopvang [Parents about child care]. Amsterdam: SCO-Kohnstamm Instituut, rapport 349.

Vedder, P. (ed.) (1992). Measuring the quality of education. Amsterdam: Swets \& Zeitlinger.

Vedder, P. (1995). Antilliaanse kinderen; taal opvoeding en onderwijs op de Antillen en in Nederland [Antillian children's language and education in the Antilles and in the Netherlands]. Utrecht: Jan van Arkel.

Vedder, P., Bouwer, E., \& Pels, T. (1996). Multicultural child care. Clevedon: Multilingual Matters.

VNG (1991), Gemeenten en kinderopvang. Modelverordening [Communities and child care: A model for regulations]. The Hague: VNG. 